\title{
UNIVERSITY RESEARCH ETHICS CLEARANCES: SAFETY NETS, OR A FALSE SENSE OF LEGAL IMMUNITY?
}

\section{J. Beckmann}

Research fellow

Edu-HRight Unit (Education and Human Rights in Diversity)

North West University

e-mail: johan.beckmann21@gmail.com

\section{ABSTRACT}

Ethics reviews are major events in the life of a researcher at a university. Ethics clearances for research projects are time consuming and sometimes slow down research progress. Because of the serious implications of unethical research conduct it follows that ethics committees should review research project applications meticulously and critically. They should attempt to ensure that, in all projects that are approved, the human respondents and participants are protected and suffer no harm that could have been prevented.

Issues of ethical and moral conduct and behaviour are fiercely debated on an on-going basis in many walks of life. The issues of ethics and morality overlap notions of the law in some respects (for example they are all about choices between what is right and what is wrong). However, there seems to be a lack of awareness in academic circles about the possible legal repercussions of unethical conduct in research. References to the law are almost non-existent in discussions of research ethics. References that do occur tend to display too narrow a view of what the law is and do not reflect an ability to give due consideration to the legal implications of the granting of ethics clearance. Very little attention seems to be given to alerting researchers and clearance-granting agencies to the legal risks to which they might be exposed during and subsequent to the conducting of a research project.

This article investigates the protection that ethics review protocols (particularly in the human sciences at higher education institutions) offer researchers and their institutions against legal ramifications emanating from research projects where participants do suffer harm. In investigating the protection I examine the terms 'ethics', 'morality' and the 'law' and relate them to ethics clearance applications. I also discuss some possible legal consequences of unethical conduct emanating from research.

The main finding is that research ethics protocols may offer less protection against legal implications of ethical misconduct than would generally be thought to be the case. There seems to be a need to raise awareness of possible legal consequences associated with research malpractices. There also seems to be a need for and guidelines and training that would facilitate such awareness.

Keywords: ethics clearance, ethics, morality, the law, (vicarious) liability, harm, breach of contract, delict, informed consent, risk 


\section{INTRODUCTION}

The process of applying for, considering and approving ethics clearances for research projects applications is a time-consuming process and often has the effect of slowing down research progress. Because of the serious implications of unethical research conduct it is unavoidable that ethics committees should review research project applications meticulously and critically. They should attempt to ensure that, in all projects that are approved, the human respondents and participants are protected and suffer no harm that could have been prevented.

\section{Ethical principles}

The 'Belmont Report: Ethical Principles and Guidelines for the Protection of Human Subjects of Research, Report of the National Commission for the Protection of Human Subjects of Biomedical and Behavioral Research' (https://en.wikipedia.org/wiki/Belmont_Report) was published by the National Commission for the Protection of Human Subjects of Biomedical and Behavioral Research in the USA in 1978. This report encapsulated three ethical principles for using human subjects for research as follows:

1. Respect for persons: This requires the protection of the autonomy of all people and treating them with courtesy and respect and allowing for informed consent. Researchers are also enjoined to be truthful and conduct no deception (https://en.wikipedia.org/wiki/ Belmont_Report). Horner (2003, 268) emphasises that this principle fosters and enhances the self-determination (self-governance) of others and refrains from interfering with free choice and strives to protect vulnerable persons as much as possible.

2. Beneficence: The concept of beneficence refers to the 'Do no harm' philosophy and attempts to maximize benefits for the research project while minimizing risks to the research subjects (https://en.wikipedia.org/wiki/Belmont_Report). According to Horner (2003, 268) the aim of beneficence is to benefit others and balance good results over potential harm.

3. Justice: In research this principle requires researchers to ensure that reasonable, nonexploitative, and well-considered procedures are administered fairly and that the costs and benefits to potential research participants are distributed fairly and equally (https://en.wikipedia.org/wiki/Belmont_Report).

Horner (2003, 268) refers to a fourth principle namely 'nonmaleficence' which she defines 
as action to avoid harm and to 'balance risks and the seriousness of potential harms against potential benefits to balance risks'.

These principles are widely regarded as the bedrock of acceptable ethical research practice.

Shore (2006) criticizes the Belmont Report for not taking into account more appropriate aspects of ethical and moral conduct and behaviour such as political, governance, ethnic, cultural, gender, economic, language and environmental considerations. All of these aspects are under constant scrutiny as is the question of how they should be weighted or prioritised (Vollmer 2010).

\section{Ethics, morality and law}

The issues of ethics and morality overlap with notions of the law in a number of ways. Horner (2003), a jurist, wrote an article which provided introductory concepts regarding morality, ethics and law. The very fact that a jurist apparently wrote this article for an audience consisting mainly of speech and language practitioners in the health professions seems to suggest a response to an articulated need to clearly differentiate the three terms (Horner 2003, 263). This article was a contribution to a guest-edited volume of Ethical, Moral, and Legal Issues in Speech and Language Pathology.

One could postulate that the article also addressed confusion about the three terms or neglect of one or more of them amongst other things in research as she quotes the three guiding ethics principles captured in the Belmont Report (Horner 2003, 268). It might also be that the similarity of the three terms could lead a researcher to believe that, should he or she comply with the requirements of one of them (for example ethics requirements) in regard to a research project, he has satisfied all of them (including the legal ones). I will argue that such a stance would be mistaken.

A brief discussion of Horner's (2003) analysis of the interrelatedness of morality, ethics and the law will suffice for the purposes of this article. Horner (2003, 263) points out that morality refers to 'a set of values that are widely shared and relatively stable within a community’. In support of this statement she quotes Beauchamp and Childless (1994) who define morality as 'social conventions about right and wrong human conduct that are so widely shared that they form a stable (although usually incomplete) communal consensus' (Horner 2003, 264). Moral values therefore pertain to what is 'right or wrong, good or bad' (Horner 2003, 264). In regard to values, Horner (2003, 264) concludes that moral values are the 'foundations of our obligations (our duties) toward one another'. 
Horner (2003, 264-265) views ethics as a branch of philosophy that examines 'human conduct focusing on the rightness and wrongness, goodness or harmfulness of actions'. She distinguishes amongst other things the following three types of ethics (Horner 2003, 265): normative ethics is about what should or ought to be done, descriptive ethics portrays actual values and actions while research ethics is applied to 'those who conduct research involving human (or animal) participants, to assure the integrity of the process and to protect the interests of participants' (Emphasis added).

In discussing the law and the similarities and differences between morality and the law, Horner (200, 269-270) suggests that law and morality establish the 'the ground rules for good behavior'. A major difference between the two concepts is that law is written by legislatures and courts and not by society and that is justiciable and enforceable in a court of law. Where morality helps people decide what they should do, the law tells people what they must do (Emphasis by the quoted author). The law entails a mix of rights and obligations (also in regard to the conducting of a research project by a researcher). Horner (2003, 270-272) points out that there are various types of law namely statutory law, administrative law, common law and constitutional law. Horner writes about USA law but in South Africa too there are various types of law and it would be wrong to think of law only in terms of statutory law.

Horner concludes her analysis with a striking summary of the relationship between the law, morality and ethics. She says (Horner 2003, 273) that 'the law tells us what we must do; morality tells us what we should do. Law is the floor upon which moral agents walk. Both law and morality exhort us to act in ways that foster well-being within our communities' (Emphasis added by the quoted author). If one bears in mind that ethics is the study of morality, it becomes clear that the three concepts are inextricably bound and that a researcher who neglects or omits any one of them is seriously amiss.

\section{Inadequate consideration of the law in discussions of research ethics}

There seems to be a lack of awareness and appreciation in academic circles of the possible legal repercussions of unethical conduct in research even if the law and ethics are clearly very similar and are applied to the same conduct. References to the law are almost non-existent in discussions of research ethics and, where they do occur, they tend to display a narrow view of what the law is and do not reflect an ability to give due consideration to the legal implications of a an inability or failure or omission to prevent psycho-physical harm to participants emanating from a research project. Wiles $(2013,19-21)$ exemplifies the scant attention given to legal implications in the literature on research and research ethics. Her book contains 111 
pages of which just slightly more than two are devoted to legal regulation. Furthermore, she seems to view the law predominantly as statutory law although she touches very briefly on common law and some human rights.

Human-Vogel and Coetzee $(2011,167)$ argue that 'ethics review is a necessary social practice that serves to encourage researchers and institutions to be accountable to the society they serve. In addition, ethics review can act as a key safety net for all academic researchers, in particular those who plan to involve vulnerable participant groups such as children, ....' One cannot fault their view that ethics review is a necessary social practice to encourage accountability. However, their reference to the ethics review process as a safety net almost certainly alludes to the protection it supposedly affords against possible legal action following untoward research practices. It is an unavoidable question whether that can be viewed as the purpose of ethics reviews. Furthermore, they have not put forward reasons for viewing ethics review processes as safety nets against the coercive functions of the law namely penalties for misconduct in amongst other things research projects (Horner 2003, 270).

\section{Objective of the article}

This article investigates the protection that ethics review protocols (particularly in the human sciences) offer researchers and their institutions against legal ramifications emanating from research projects where participants do suffer harm. In the process, I examine the terms 'ethics', 'morality' and the 'law' and relate them to ethics clearance applications. I also discuss some possible legal consequences of unethical conduct of which there seems to be inadequate appreciation among researchers and even ethics clearance-granting institutions. My observations are on research in the social sciences and when referring to 'researchers' I refer especially to academics and postgraduate students.

\section{AN ACADEMIC INSTITUTION AND ITS EMPLOYEES AND STUDENTS}

Although guidance, accountability and oversight in respect of the conduct of research may form part of a university's brief, the limited scope of this article does not allow a thorough discussion of all the functions and duties of an academic institution and the legal implications thereof. I can also not examine the full scope of the employment relationship between an academic institution and its employees, and the various reciprocal rights and duties of the contracting parties in a research project. Should the issue of liability for harm suffered during research be raised, the employer-employee relationship, including acceptance of vicarious liability (as discussed in the section on 'Aspects of liability and vicarious liability' below) for the wrongs 
committed by an employee, is relevant when considering possible compensation for harm.

Similarly, I cannot explore in depth the specific legal relationship that exists between enrolled master's and doctoral students and the qualification-awarding institution concerned regarding the teaching of specific aspects of the undertaking of research, and the supervision of student research. Where necessary, relevant aspects will be highlighted for the purposes of this article.

\section{MORALITY, ACCOUNTABILITY AND LEGAL LIABILITY IN RESEARCH}

\section{Morally acceptable conduct}

Research ethics concerns what is wrong and what is right in the conduct of research. Because scientific research is a form of human conduct, it follows that such conduct has to conform to generally accepted norms and values. As in any sphere of human life, certain kinds of conduct are morally acceptable, while others are not. Scientific (scholarly) communities have developed codes of conduct in order to regulate the behaviour of members who engage in research with human participants, and such codes of conduct are usually enforced through professional societies and associations, universities, and universities of technology, and, in some cases, funding agencies (Mouton 2001, 238-239).

\section{Accountability and legal liability}

The most important principle that guides the relationship between researchers and the rest of society is that of accountability. This principle implies that scientists/researchers are to some degree accountable to society for what they do. This accountability does not involve the specifics of research projects, but refers to a general obligation that researchers have to conduct their craft in a socially responsive and responsible manner (Mouton 2001, 241-242). Academic freedom demands that a profession (in this case the academic community) regulate its own practices and its own members internally (Bruhn, Zajac, Al-Kazemi and Prescott 2002, 462).

Morally unacceptable conduct, or transgression of a professional code of conduct, may constitute unethical research, but it does not necessarily cause loss or damage, or constitute a breach of contract which may lead to a claim for reparation (compensation) based on the legal principles of breach of contract or delict.

The fundamental premise in South African law is that damage (harm) rests (lies) where it falls, that is, each person must themselves bear the damage that they suffer (res perit domino). This principle also applies to damage that a human subject may suffer during or because of a 
research project.

However, damage does not always rest (lie) where it falls. There are indeed certain instances where the burden of damage is shifted from one individual to another, with the result that the latter incurs the obligation to bear the former's damage, or to provide compensation for it. For example, where damage arises from delict, the wrongdoer is legally obliged to compensate the aggrieved party. In general terms, the law of delict thus determines the circumstances in which a person is obliged to bear the damage they have caused another, or, in other words, when they may incur civil liability for such damage. Because the wrongdoer has an obligation to compensate a person for damage or harm suffered, the person prejudiced has a corresponding right to claim compensation (Neethling, Potgieter and Visser 2001, 3).

It is important to note that a delict is not the only form of unwarranted or inadmissible conduct of which the law takes cognisance. For the purposes of this article, and with regard to potentially ethically unacceptable research behaviour, a distinction can be made between a delict and a breach of contract (Neethling, Potgieter and Visser 2001, 6).

Like a delict, a breach of contract constitutes a form of wrongful conduct in private law in South Africa. As with a delict, breach of contract is normally an act by one person (a contracting party (participant in an agreement) such as a researcher), which, in a wrongful and culpable (blameworthy) way, causes damage to another person (another contracting party such as a research participant). In the context of this article the agreement between the researcher and the participant as embodied in a letter of informed consent may be viewed as a contract or agreement which is subject to the law. The primary remedy for (consequence of) breach of contract is to force the guilty party to fulfil or execute the contract. Claiming for damages as a remedy plays only a secondary role in regard to breach of contract. However, one and the same act may render the wrongdoer liable ex contractu (from breach of contract) as well as ex delicto (from commission of a delict) (Neethling, Potgieter and Visser 2001, 6-7).

\section{RESEARCH ETHICS REVIEWS}

Nancy Walton (n.d.) provides a succinct overview of research ethics reviews. She enumerates a number of objectives of research ethics reviews, which have a bearing (Walton n.d.).

1. The first and broadest objective [of ethics reviews] is to protect human participants.

2. The second objective is to ensure that research is conducted in a way that serves the interests of individuals, groups and/or society as a whole.

3. The third and final objective is to examine specific research activities and projects for their ethical soundness, looking at issues such as the management of risk, protection of 
confidentiality and the process of informed consent.

The objectives Walton mentions seem to resonate with the ethical principles as articulated in the Belmont Report and analysed and discussed by Horner (2003) and Shore (2006) (see 'Introduction' above). It is noticeable that she does not regard making researchers aware of the possible legal consequences of unethical conduct as being an objective of ethics reviews.

\section{CHALLENGES ASSOCIATED WITH ETHICS REVIEWS}

Researchers have argued that reviews of research protocols at academic institutions can complicate research participation considerably (Human-Vogel and Coetzee 2011, 166). Dingle and Stuber (2008, 188), cited in Human-Vogel and Coetzee (2011, 166), comment that 'taking the most ethical and professional path can be inconvenient, financially disadvantageous, timeconsuming, frustrating, or complicated'. Fitzgerald and Phillips (2006, 47), in Human-Vogel and Coetzee (2011, 166), refer to the complications caused by 'the cumbersome and costly process of ethics review'.

Despite such criticism, Human-Vogel and Coetzee $(2011,167)$ argue that ethics reviews are 'a necessary social practice that serves to encourage researchers and institutions to be accountable to the society they serve'. Human-Vogel and Coetzee $(2011,167)$ agree with Bruhn et al. $(2002,462)$ that '[a]cademic freedom demands that the academic community regulate its own practices and its own members internally'. Furthermore, Human-Vogel and Coetzee (2011, 167) point out that both Bruhn et al. (2002, 461) and Wolpe $(2006,1023)$ highlight the responsibility of academic researchers and their universities towards society, in general, and towards the communities and the students that they serve, in particular.

\section{THE INTERACTION BETWEEN THE RESEARCHER AND THE SUBJECT (THE PARTICIPANT, OR THE RESPONDENT)}

\section{Informed consent as a contract (agreement) or requirement for research}

Citing Jefford and Moore (2008, 485), Wolpe (2006, 1024), and Haggerty (2004, 405), HumanVogel and Coetzee $(2011,176)$ conclude that ' $[t]$ he necessity for informed consent in research is widely acknowledged [...] although researchers may disagree as to the best way of obtaining informed consent'.

Human-Vogel and Coetzee $(2011,176)$ state that from a modernist perspective, 'informed consent is viewed as a contract or a requirement that is dispensed with at the start of the study'. Although the word 'contract' suggests a definite and considered commitment to an activity, the 
phrase ‘is dispensed with’ seems to suggest that not much time and effort is spent on obtaining informed consent. That would fly in the face of the legal requirement that reviewers of ethics applications and the drafters of such application apply their minds properly to the various parts of the research project. Should a participant suffer harm and it transpires that the reviewer and/or the researcher did not apply their mind to the informed consent required, such researcher could face legal action including claims for compensation.

They also mention that in general, postmodernist researchers 'experience problems with informed consent because it can be viewed as a quality of the emerging relationship between the researcher and the participant' (Human-Vogel and Coetzee 2011, 176). While I argue that the possible legal liability that a researcher may face should be one of the considerations when ethics reviews are undertaken, Human-Vogel and Coetzee (2011, 176-177) make the valid point that the information that researchers put before ethics committees is the:

[o]nly information reviewers have at their disposal to judge the extent to which researchers are ethically aware, and whether they have applied sound reasoning in terms of the decisions they will make in respect of their potential participants, as well as assessing potential risk to participants. Submission of an application to a committee is no guarantee of how the researcher will ultimately conduct the actual research, and it makes it difficult for reviewers to be able to detect and comment on possible legal consequences.

However, this fact does not seem to absolve reviewers and/or their institutions from possible liability for wrongful conduct during the research process. The awareness of this problem requires strategies to overcome it. Mere acceptance that it happens will not satisfy the demands of the law that participants in research be protected.

A further problem pointed out by Human-Vogel and Coetzee (2011, 177), citing Jefford and Moore (2008, 486), is that ' $[\mathrm{t}]$ he signing of informed consent is recognised as a symbolic act that does not necessarily indicate understanding on the part of the participant'. They argue that '[e]thics committees need to know how the applicant proposes to obtain informed consent' (Human-Vogel and Coetzee 2011, 177). Jefford and Moore (2008, 486), cited in Human-Vogel and Coetzee (2011, 177), mention that participants place a great deal of trust in the researcher, and that they are prepared to consent to more risky research even if less risky options are also presented to them. This could be an indication of the trust of participants that the researcher will not unnecessarily put them in harm's way.

Providing information about risk and benefit is a key aspect of informed consent (Jefford and Moore 2008, 486, cited in Human-Vogel and Coetzee 2011, 178). In the majority of the protocols that they analysed, reviewers regarded it as a problem that researchers did not make formal statements to the participant about the possible benefits of participation in the research, 
or, otherwise, the nature of the risk, even if negligible, associated with participation (Jefford and Moore 2008, 487).

The limited protection that ethics reviews afford participants is spelt out by Human-Vogel and Coetzee $(2011,178-179)$ as follows:

It can be argued that researchers can still behave unethically despite an acceptable letter of informed consent and ethics review. Ethics committees cannot be expected to regulate the personal integrity of applicants. However, the letter of informed consent remains an important document indicating the extent to which applicants considered the ethical dimensions of their proposed study.

The question about what institutions under whose auspices researchers operate could do to better protect participants and researchers alike inevitably arises from the above matter-of-fact comment that ethics committees cannot be expected to regulate the personal integrity of applicants. The fact that committees cannot actually regulate all research behaviour does not obviate the possibility of harm for the participants, and the possibility of liability being incurred by the researcher. It also does not absolve the ethical clearance-awarding agency of all blame in the case of unethical conduct.

However, this article proposes that even if research ethics reviews neglect or do not consider the possible legal implications and consequences of unethical research practices, the physical and psychological (emotional) well-being (psychophysical integrity) of all people (including research participants) is protected by law. Violation of a participant's psychophysical integrity may result in a wrongdoer being compelled to make good the harm they may have caused in the course of a research project.

\section{Informed consent and information regarding risk and benefit}

Jefford and Moore $(2008,489)$ note that disclosure of facts about a planned research project to a potential participant requires not only a statement of the facts, but also that the researcher promotes the participant's understanding of the research project, as well as the voluntary nature of their participation, among other things, by using easily understandable short words and short sentences. Limits or threats to privacy and confidentiality as a result of the particular type of sampling strategy employed represent risks, to which potential participants should be alerted. Where applicable, persons invited to participate in a research project should also be made aware if there is an absence of direct benefit to them from participation in the project (Human-Vogel and Coetzee 2011, 178). It is conceivable that failure to disclose details about possible risks associated with participation in a research project, as well as an absence of benefits, could lead to legal repercussions for the researcher(s) and the authority issuing the ethics clearance should 
an undisclosed risk materialise and harm the participant.

Walton (n.d.) points out that peculiar kinds of ethical issues arise in the humanities and social sciences research, which is the lens through which this article is approached. She states that ' $[\mathrm{n}] \mathrm{ew}$ and emerging methods of conducting research, such as auto-ethnography and participatory action research raise important but markedly different ethical issues and obligations for researchers'. The issues are different from research within the discipline of medicine, for example, or research within the discipline of physics.

Although the statement that research methods such as auto-ethnography and participatory action research are new and emerging is debatable, the statement that '[r]esearch involving vulnerable persons, which may include children, persons with developmental or cognitive disabilities, persons who are institutionalized, the homeless or those without legal status, also raises unique issues in any research context' (Walton n.d.) is fairly indisputable. One can add that the law would require special care on the part of researchers not to harm the psychophysical integrity of the subjects (the participants, or the respondents). However, like all other persons, researchers are susceptible to the notion that such vulnerable participants are beings with less dignity than other 'normal' human beings, and that vulnerable participants are therefore not deserving of a particularly high level of protection, because the consequences of untoward research behaviour towards them are deemed to be less serious than the consequences of untoward research behaviour towards other subjects, or participants, or respondents. The law will not approve of conduct that reflects such an attitude towards vulnerable participants.

Before I turn to the issue of legal consequences of the violation of participants' rights, as discussed in the section 'Aspects of liability and vicarious liability' below, I will focus on the basic rights of research subjects.

\section{BASIC RIGHTS OF SUBJECTS IN RESEARCH, AND HOW THESE RIGHTS AFFECT THE CONDUCT OF RESEARCH}

It is important to remember that Section 16(1)(d) of the Bill of Rights (Chapter 2) in the Constitution of the Republic of South Africa of 1996 provides for the right of everyone to academic freedom and freedom of scientific research (Emphasis added). Researchers' rights are therefore embedded amongst other things in the above-mentioned subsection of the Constitution of 1996. However, the Bill of Rights also contains a general limitation clause, which provides that the rights in the Bill of Rights may be limited in terms of law of general application, to the extent that the limitation is reasonable and justifiable in an open and democratic society based on human dignity, equality, and freedom, taking into account a 
number of listed and relevant factors. The right to academic freedom and freedom of research can thus also be limited. A researcher that oversteps the boundaries of academic freedom and freedom of research could thus expose themselves to legal action and find their right to academic freedom and research restricted or limited.

Within the context of research ethics, Mouton (2001, 243-246) lists some of the most basic rights of subjects in research, and indicates how these rights affect the conduct of research. These rights are

(a) the right to privacy (including the right to refuse to participate in research),

(b) the right to anonymity and confidentiality,

(c) the right to full disclosure about the research (informed consent), and

(d) the right not to be harmed in any way (physically, psychologically, or emotionally).

In addition, 'vulnerable' groups (such as children, the aged, and the mentally disabled) may have additional specific rights that should be noted and respected as part of a researcher's contractual obligations.

\section{The right to privacy (including the right to refuse to participate in research)}

Human-Vogel and Coetzee $(2011,178)$ analysed ethics reviews and found that the majority of researchers stated in their applications that the research did not provide any direct benefit to the participants at all, but that they neglected to state this in the letter of informed consent, presumably because it could have adversely affected participation. It can be argued that researchers can still behave unethically even if there is an acceptable letter of informed consent and an ethics review. In law, negligence by a researcher to disclose the absence of benefits associated with participation in a research project could have serious implications for the researcher, as it could negatively impact on the relationship of trust that should exist between the researcher and the subject.

Mouton (2001, 243) points out that in an increasingly public and transparent world, researchers have to be extremely watchful in respecting the right of subjects to privacy. This right to privacy in the field of research is expressed more concretely in the following 'rules': the right to refuse to be interviewed, the right to answer or not to answer telephonic or email questionnaires, the right to refuse to answer any question, and the right not to be interviewed at meal times or at night, or for long periods of time. A delictual violation of these rules could lead to legal action against a researcher. 


\section{The right to anonymity and confidentiality}

Participants as providers of information have the right to remain anonymous. This right should be respected both where it is promised explicitly and where no clear understanding to the contrary has been reached (Mouton 2001, 243). While anonymity refers to the principle that the identity of the individual is kept secret, the principle of confidentiality refers to the information gathered from subjects. Such information should be protected even if it enjoys no explicit legal protection or privilege (Mouton 2001, 244).

\section{The right to full disclosure about the research (informed consent)}

In the section above, I discussed the necessity of informed consent, which is widely acknowledged in research. Researchers may disagree as to the best way of obtaining informed consent. It was also indicated that informed consent is sometimes viewed as a contract (agreement) or a requirement that is dispensed with at the start of a study.

I would argue that as far as informed consent is a contractual requirement, it remains part of the contract (the entire research process) from start to finish, and can be revoked at any time (Mouton 2001, 244).

If the researcher fails to abide by the agreement of full disclosure required for informed consent, they will be in breach of contract, and may face legal action. In the section above on 'Morality, accountability and legal liability in research', attention was drawn to the fact that breach of contract constitutes a form of wrongful conduct in private law in South Africa.

\section{The right not to be harmed in any way (physically, psychologically, or emotionally)}

The process of conducting research must not expose the subjects to substantial risk of personal harm. Informed consent must be obtained when the risks of the research are greater than the risks of everyday life. Even where modest risk or harm is anticipated, informed consent must be obtained. Experimentation of any kind is usually associated with a greater risk of potential harm to subjects. Potentially harmful experimentation would include

(a) physiological or psychological experiments,

(b) procedures that are intrusive, and

(c) steps involving responses to an abnormally stressful stimulus or activity (stressful beyond the normal experience of the subject, including personal embarrassment) (Mouton 2001, 245). 
For the purposes of informed consent, where experiments involve a risk of potential harm to the subject, this must be disclosed to the subject, and if the subject does not have legal status (locus standi in iudicio) to grant permission for the experiment to be conducted (for example when the subject is a child), consent should be obtained from the person who is legally responsible for that subject (Mouton 2001, 245).

In this regard, special mention should be made of the rights of vulnerable groups of persons to protection. Examples of such groups are children, mentally disabled persons, the aged, prisoners, psychiatric patients, and so on. This could also apply to illiterate persons, persons who have low social status, or persons who are unfamiliar with social research (Mouton 2001, 245).

\section{ASPECTS OF LIABILITY AND VICARIOUS LIABILITY}

The issue of liability or vicarious liability for wrongful deeds has already been discussed to some extent in the section on 'Morality, accountability and legal liability in research'. In this section I intend to provide more clarity on the matter of liability that could arise from unethical research conduct. The seriousness of the possible legal action merits this brief elucidation.

\section{The general principles of vicarious liability}

In the recent Constitutional Court case of $F v$ Minister of Safety and Security and Another, the Court dealt with the general principles of vicarious liability and how they had evolved until the so-called case of $\mathrm{K}$ was decided.

The Court stated that vicarious liability means that a person may be held liable for the wrongful act or omission of another even if the former did not, strictly speaking, engage in any wrongful conduct. Such liability would arise where there is a particular relationship between those persons, such as an employment relationship.

\section{When may a person such as an employer be vicariously liable for a wrongful deed committed by someone else?}

As a general rule, an employer is vicariously liable for the wrongful acts or omissions of an employee committed within the course and scope of their employment, or while the employee was engaged in any activity reasonably incidental to (needed in) the course and scope of their employment. Furthermore, the Court stated that two tests apply when determining vicarious liability. One test applies when an employee commits the delict while going about the employer's business. This is generally regarded as the standard test. The other test finds 
application where wrongdoing takes place outside the course and scope of the employee's employment. These are known as deviation cases. Sometimes the latter is referred to as 'being on a frolic of your own'.

\section{Actionable wrongs or delicts}

It is commonly recognised that an actionable wrong or delict (a wrong or delict in regard to which legal action could be taken) has five elements, or requirements, namely

(a) the commission or omission of an act (actus reus)

(b) which is unlawful or wrongful (wrongfulness)

(c) and is committed negligently or with a particular intent (culpa, or fault),

(d) and which results in or causes harm (causation) and

(e) the suffering of injury, loss, or damage (harm).

A court will decide whether someone is liable or vicariously liable to compensate someone for a wrongful deed or delict by assessing his or conduct in the light of the above requirements. The court will therefore ask and answer the following questions in regard to an allegedly wrongful deed that has led to harm:

(a) Was an act committed?

(b) Was the act wrongful or unlawful?

(c) Was the act committed negligently or intentionally?

(d) Did the act cause the harm?

(e) Did the act cause injury, loss or harm?

A court may impose a suitable sanction that will compensate the one who suffered the harm.

\section{Liability for loss or damage because of an omission (negligence)}

The locus classicus in respect of negligence in South African law is the case of Kruger $v$ Coetzee at 430E-F, where Holmes JA said the following:

For the purposes of liability, culpa (fault) arises if

(a) a diligens paterfamilias (good, caring father of a family) in the position of the defendant (the alleged perpetrator of the wrongful deed)

(i) would foresee the reasonable possibility of his conduct injuring another in his person or property and causing him patrimonial (financial) loss, 
(ii) and would take reasonable steps to guard against such occurrence,

(b) and the defendant failed to take such steps.

This means that if the alleged wrongdoer (in this case the researcher) (a) could (like a good father of a family) have foreseen the possibility of their action causing personal injury or material loss (of property) or patrimonial loss to another (the participant), (b) could have taken steps to guard against the injury or loss and (c) failed to take such steps, their omission or act will attract liability for the resulting harm, injury or damage.

It appears highly unlikely that a social sciences researcher would wilfully and culpably commit a wrongful act that would result in (or cause) harm to their participants. It is more likely that a social sciences researcher could cause harm negligently, through commission of a wrongful act. A culpable act could foreseeably negligently cause harm to a participant if one or more of the basic rights mentioned in the section above on 'Basic rights of subjects in research, and how these rights affect the conduct of research' is violated, where the researcher would then be held liable for such damage. The fact that harm could take many forms (it could for example be physical, psychological or emotional in nature and could lead to injury or material or patrimonial loss) seems to open up more possibilities for intentional and unintentional infringements of the law regarding research and ethical conduct.

\section{CONCLUSION}

The challenging morality, ethics and the law conundrum also manifests itself in ethics reviews and is not likely to be resolved soon. It appears that ethics reviews do not offer as much protection against legal action in terms of the law of delict to researchers and their employers as they would like to believe because of a general ignorance regarding the nature of the relationship between ethics and the law which leads to certain role-players mistakenly believing that ethics subsumes the law and that an ethics clearance certificate may render the holders thereof immune to the law and put them out of reach of the law.

It seems that insufficient information may be conveyed to prospective researchers about the legal risks they may be running when conducting research. It may also be that there is insufficient human capacity in research institutions to provide such information and to offer training and continuous development in this regard.

It is probably not good enough to say that an ethics clearance certificate cannot prevent unethical conduct resulting in harm to the subjects in research. One may ask the question whether the apparent awareness on the part of reviewers of ethics applications that their contribution to the research process is perhaps not going to help preventing harm or damage to 
subjects should not lead to more concerted efforts to ensure that more information about the legal risks associated with research is available to researchers. This should include training on the rights of participants as well as on the rights and responsibilities of researchers.

It would seem that ethics reviews need to be revisited. The ethics review process needs to address the possible liability or vicarious liability of researchers and or institutions for injury, harm or damage resulting from research activities. More attention needs to be given to training on how to conduct ethically irreproachable research that will only in the most exceptional and unforeseeable of cases attract legal liability.

The magnitude of the liability attracted or of the sanctions (punishment) that could be imposed is extremely difficult to quantify. However, if one considers the consequences of violations of constitutionally entrenched fundamental rights such as personal dignity, anonymity and privacy in the research process, it is clear that sanctions resulting from being held liable or vicariously liable for wrongful actions or negligence in this regard could have substantial financial and other consequences for the researcher (be it a student or an academic) and/or the institution concerned. It is 'within the realms of possibility' that a researcher may have their academic freedom (regarding academic research) limited, possibly resulting in a loss of employment. It is also conceivable (although fairly unlikely) that a part of an institution or an entire institution may have their authority to be involved in research and research development restricted or withdrawn as a result of research malpractices amounting to unethical research conduct. Research funding or incentives may be withdrawn or withheld.

It seems highly advisable that researchers (including supervisors) and institutions should take cognizance of the possible consequences of unethical conduct and take steps to avoid possible legal action resulting from impermissible conduct. Consideration needs to be given to ways and means of improving the preparation of researchers and all the research and researchrelated activities of an institution with regard to the existing legal frameworks and directives. More important though is support for and supervision of researchers 'in the field', for that is where risky unethical conduct takes place. The possible results of a misguided belief that certain researchers have been rendered immune to the law through the research ethics review process are such that the legal literacy on research issues needs to become a non-negotiable requirement for participation in research activities at research institutions.

\section{ACKNOWLEDGEMENTS}

I wish to express my sincere gratitude to Advocate Justus Prinsloo, formerly of the SuidAfrikaanse Onderwysersunie and the University of Pretoria, for his invaluable assistance. 
Errors in matters legal are entirely my own fault.

This article was language-edited by a freelance language editor, Anthony Sparg. He has edited several academic journal articles and master's and doctoral theses in the field of education. He has an MA cum laude in African Languages (isiXhosa), an MA cum laude in Linguistics, and a Higher Diploma in Education.

\section{REFERENCES}

Beauchamp, T. L. and J. F. Childless. 1994. Principles of biomedical ethics. $4^{\text {th }}$ Edition. New York: Oxford University Press. Quoted in Horner (2003: 264).

Bruhn, J. G., G. Zajac, A. A. Al-Kazemi and L. D. Prescott Jr. 2002. Moral positions and academic conduct: Parameters of tolerance for ethics failure. The Journal of Higher Education 73(4): 461493.

Dingle, A. D. and M. I. Stuber. 2008. Ethics education. Child and Adolescent Psychiatric Clinics of North America 17(1): 187-207.

F v Minister of Safety and Security and Another (CCT 30/11) [2011] ZACC 37; 2012 (1) SA 536 (CC); 2012 (3) BCLR 244 (CC); (2012) 33 ILJ 93 (CC); 2013 (2) SACR 20 (CC) (15 December 2011).

Fitzgerald, M. H. and P. A. Phillips. 2006. Centralized and non-centralized ethics review: A five nation study. Accountability in Research 13(1): 47-74.

Haggerty, K. D. 2004. Ethics creep: Governing social science research in the name of ethics. Qualitative Sociology 27(4): 391-414.

Horner, Jennifer. 2003. Morality, ethics, and law: Introductory concepts. Seminars in Speech and Language 24(4): 263-274.

Human-Vogel, S. and S. Coetzee. 2011. Challenges associated with ethics review of educational research at a South African university. Acta Academica 43(2): 165-192.

https://en.wikipedia.org/wiki/Belmont_Report (accessed 21 November 2016).

Jefford, M. and R. Moore. 2008. Improvement of informed consent and the quality of consent documents. The Lancet Oncology 9(5): 485-493.

Kruger v Coetzee. 1966(2) SA 428(A).

Minister of Safety and Security $v$ Van Duivenboden (209/2001) [2002] ZASCA 79; [2002] 3 All SA 741 (SCA) (22 August 2002).

Mouton, J. 2001. How to succeed in your masters and doctoral studies: A South African guide and resource book. Pretoria: Van Schaik.

Neethling, J., J. M. Potgieter and P. J. Visser. 2001. Law of delict. 4th Edition. Durban: Butterworths.

Shore, Nancy. 2006. Re-conceptualizing the Belmont Report: A community-based participatory research perspective. Journal of Community Practice 14(4): 5-26. Available at https://en. wikipedia.org/wiki/Belmont_Report (accessed 21 November 2016).

Vollmer, Sara, H. and George Howard. 2010. Statistical power, the Belmont Report, and the ethics of clinical trials. Science and Engineering Ethics: 675-691. Available at https://en.wikipedia.org/ wiki/Belmont_Report (accessed 21 November 2016).

Walton, N. n.d. What is research ethics? Blog at WordPress.com. https://researchethics.ca/what-isresearch-ethics/ (accessed 5 October 2016).

Wiles, Rose. 2013. What are qualitative research ethics? London: Bloomsbury Publishing Plc.

Wolpe, P. R. 2006. Reasons scientists avoid thinking about ethics. Cell 125(6): 1023-1025. 